\title{
Muito além de Baco: uma análise sobre as micro e pequenas cervejarias da Região da Serra Gaúcha, Estado do Rio Grande Sul, Brasil
}

\section{Eléia Righi ${ }^{1}$ e Raquel de Jesus Motta Velasquez ${ }^{2}$}

${ }^{1}$ Universidade Estadual do Rio Grande do Sul. Unidade Universitária Caxias do Sul. Avenida Júlio de Castilhos, 3947. Bairro Cinquentenário. Caxias do Sul-RS, Brasil (CEP 95010-005). E-mail: eleia-righi@uergs.edu.br.

${ }^{2}$ Universidade Estadual do Rio Grande do Sul. Unidade Universitária Caxias do Sul. Curso de Bacharelado em Ciências e Tecnologia de Alimentos. Avenida Júlio de Castilhos, 3947. Bairro Cinquentenário. Caxias do Sul-RS, Brasil (CEP 95010-005).

Resumo. A diversificada produção das cervejas artesanais e produtos com cerveja na receita tornou-se uma oportunidade com características inovadoras para o desenvolvimento econômico e turístico de muitos municípios em todo o Brasil. Na Serra Gaúcha, Estado do Rio Grande do Sul, Brasil, é possível verificar quanto à produção cervejeira impulsiona o crescimento da economia, trazendo mais empregos e desenvolvimento. Assim, o objetivo geral desse trabalho foi mapear e analisar as micros e pequenas cervejarias da Serra Gaúcha. A compilação dos resultados foi elaborada utilizando o SIG, software ArcGis. Na região de estudo, foram listadas 53 cervejarias pelo mapa de localização, Caxias do Sul possui o maior número de registros. A produção anual em cada cervejaria da Serra Gaúcha varia entre 15.000 e 250.000 litros, com a maioria delas produzindo cerca de 20.000 litros ao mês. Os meses de maior produção são os períodos de altas temperaturas, entre novembro e fevereiro, principalmente dos estilos tipo Lager, Pilsen e Ipa. Também se destaca a produção dos tipos Ale, Weissbier e Pale Ale, com uma proporção intermediária na produção, e em menor número as cervejas Bock e Malzbier. Com todas as informações espacializadas e analisadas foi possível propor alternativas de desenvolvimento local/regional, através do fortalecimento da cadeia produtiva do setor e da expansão da atividade turística.

Palavras-chave: Espacialização; Polos cervejeiros; Desenvolvimento sustentável.

Abstract. Much beyond Bacchus: An analysis of micro and small breweries in the Serra Gaúcha Region, State of Rio Grande do Sul, Brazil. The diversified production of craft beers and products with beer in the recipe has become an opportunity with innovative features for the economic and tourist development of many municipalities throughout Brazil. In the
Recebido

$19 / 05 / 2021$

Aceito

$24 / 11 / 2021$

Disponível on line $24 / 11 / 2021$

Publicado

$31 / 12 / 2021$

Acesso aberto

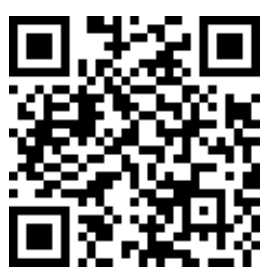

RCID

(D) 0000-0002-2766-8719 Eléia Righi

(D) 0000-0003-3181-0738 Raquel de Jesus Motta Velasquez

ISSN 2359-1412/RBGAS-2021-0053/2021/8/20/5/1333

Rev. Bras. Gest. Amb. Sustent.

http://revista.ecogestaobrasil.net 
Serra Gaúcha, State of Rio Grande do Sul, Brazil, it is possible to see how much beer production drives the growth of the economy, bringing more jobs and development. Thus, the general objective of this work was to map and analyze the micro and small breweries of Serra Gaúcha. The results were compiled using the GIS, ArcGis software. In the study region, 53 breweries were listed by localization map, Caxias do Sul has the largest number of records. The annual production in each brewery in Serra Gaúcha varies between 15,000 and 250,000 liters, with most of them producing about 20,000 liters per month. The months of greatest production are the periods of high temperatures, between November and February, mainly of the Lager, Pilsen and Ipa styles. We also highlight the production of the Ale, Weissbier and Pale Ale types, with an intermediate proportion in the production, and to a lesser extent the Bock and Malzbier beers. With all the information spatialized and analyzed, it was possible to propose alternatives for local and regional development, through the strengthening of the sector's production chain and the expansion of tourist activity.

Keywords: Spatialization; Beer poles; Sustainable development.

\section{Introdução}

As cervejarias artesanais exploram maneiras pelas quais a autenticidade é narrada como parte de um esforço contínuo para agregar valor a seus produtos e os contextos de sua produção. Um elemento central do trabalho dos produtores de bebidas artesanais é a organização do valor cultural e a participação em atos comunicativos e performativos que atribuem esse valor aos produtos e às pessoas envolvidas na sua fabricação (ThurnellRead, 2019).

As indústrias cervejeiras que seguem o conceito de artesanal se diferenciam das cervejas industriais (produzidas em massa), principalmente pelo formato de produção adotado. As artesanais possuem uma produção baseada na utilização de insumos escolhidos com a intenção de obter harmonias distintas e notórias, com processos longos de fermentação e sob o cuidado constante e direto de um mestre cervejeiro (Luz, 2020).

Em relação aos autores que trabalham com o conceito de cerveja artesanal, foi possível concluir que ela possui vários sinônimos como cervejas especiais, qualidade superior, premium, superpremium, gourmet etc. A definição mais aceita é que são produzidas em pequena escala, por um processo de fermentação relativamente lento (maior de 21 dias), sendo o processo de fabricação mais refinado, baseado em matériasprimas nobres, selecionadas e com elevado valor agregado.

Um estudo realizado em Londres, por Wallace (2019), verifica que a produção neo-artesanal é um ambiente crescente da economia cultural urbana contemporânea, assim o autor sugere a "autenticação" de meios de subsistência, gostos e lugares através da promessa tátil de "artesanal".

A expansão das micro e pequenas cervejarias no mundo e no Brasil mostra a alteração do padrão de consumo de cervejas e as próprias mudanças no mercado de cervejas ditas "artesanais", com novas formas de atividades da cultura cervejeira (Marcusso, 2015).

O crescimento dessa atividade no Brasil vem avançando de forma sustentada nos últimos anos, em 2019 somou um total de 1209 cervejarias registradas. A concentração no 
eixo Sul-Sudeste, é crescente, se confirma com mais de $80 \%$ dos estabelecimentos. 0 Estado que apresenta maior número de cervejarias é São Paulo (241) que ultrapassou o Rio Grande do Sul (236) do último levantamento para o atual (2019). Os municípios que possuem as maiores concentrações de cervejarias ainda se mantém nessas áreas. 0 Município de Caxias do Sul, em 2018 e 2019, permaneceu em quarto lugar no Brasil em relação a quantidade de cervejarias. Em 2018 possuía 16 e em 2019, 20, um crescimento de 25\% (MAPA, 2019).

$\mathrm{Na}$ abordagem de estudos sobre esses segmentos no Brasil, um dos maiores problemas refere-se à escassez de informações teóricas, definições científicas e dados estatísticos atualizadas, e coerentes sobre a sua dimensão e forma de inserção na economia, o que se constitui em uma séria dificuldade para a formulação de políticas de estímulo ao crescimento deste setor. Mesmo assim, as pequenas e microcervejarias não tendo todo esse conjunto de dados quantificados e capital para investir em mecanismos sustentáveis, começam a aderir "lentamente" a processos sustentáveis e sociais, sobretudo, para economia de água, energia e destinação correta dos resíduos, que vai além de atender a legislação ambiental.

0 mundo das cervejas artesanais, ainda tem enorme potencial para desenvolvimento, acrescido pelas rotas cervejeiras que auxiliam na difusão da cultura e no crescimento econômico de uma região (Luz, 2020). Segundo Thurnell-Read (2019), a geografia local e os simbolismos na marca de produtos em uma determinada cidade, vila ou região, possuem o valor já intrínseco a esse lugar, cultivando uma associação com as áreas de beleza natural excepcional.

Assim, este trabalho apresenta uma visão contemporânea acerca das micro e pequenas cervejarias artesanais situadas na Serra Gaúcha-RS, Brasil, com o intuito de analisar qualitativamente e quantitativamente as características de produção, socioeconômicas e ambientais, para ser possível orientar os empreendedores quanto às ações a serem tomadas na cadeia produtiva e aumentando a lucratividade das empresas.

\section{Material e métodos}

As pequenas e microcervejarias da Serra Gaúcha foram mapeadas e organizadas através da elaboração de um Banco de Dados Geográfico pelo Sistemas de Informações Geográfica (SIGs). A compilação dos resultados foi elaborada utilizando o SIG, softwareArcGis. Os dados foram disponibilizados pelo mapade localização, SIPOV/DDA/SFA-RS, ano 2019.

Em relação a análise quantitativa e qualitativa, foi aplicado um questionário semiestruturado. 0 questionário foi enviado aos participantes como também o Termo de Consentimento Livre e Esclarecido (TCLE), devidamente autorizado pelo Comitê de Ética em Pesquisa da UERGS, sob número do parecer: 4.318.512, que também teve uma versão desenvolvida no "Google Formulários", com um total de 35 perguntas a serem respondidas pelos participantes.

Nesse sentido, foram organizadas tabelas de contingência (ou tabela de frequência de dupla entrada), que segundo Triola (2011), é definida quando as frequências correspondem a duas variáveis (uma para as linhas e outra para as colunas), onde cada variável pode ser dividida em várias categorias.

Foram verificadas práticas ambientais e sociais na concepção da empresa sustentável, comogestão ambiental, produção sustentável, produção mais limpa, ecoeficiência, avaliação do ciclo de vida, ecodesign, redução energética, bem como logística reversa.

Importante tambémse tornou avaliaros gastos de insumos, água e energia elétrica mensalmente e anualmente, propondo medidas de redução, além de verificar o destino 
correto dos resíduos produzidos, levando em consideração não somente a legislação ambiental.

\section{Resultados e discussão}

Para delimitar quais os municípios que seriam analisados quanto à existência de cervejarias artesanais, foi utilizado como base o Corede Serra, formado por 32 municípios, assim, foram mapeadas as 53 cervejarias artesanais pertencentes a essa região (Figuras 1 e 2).

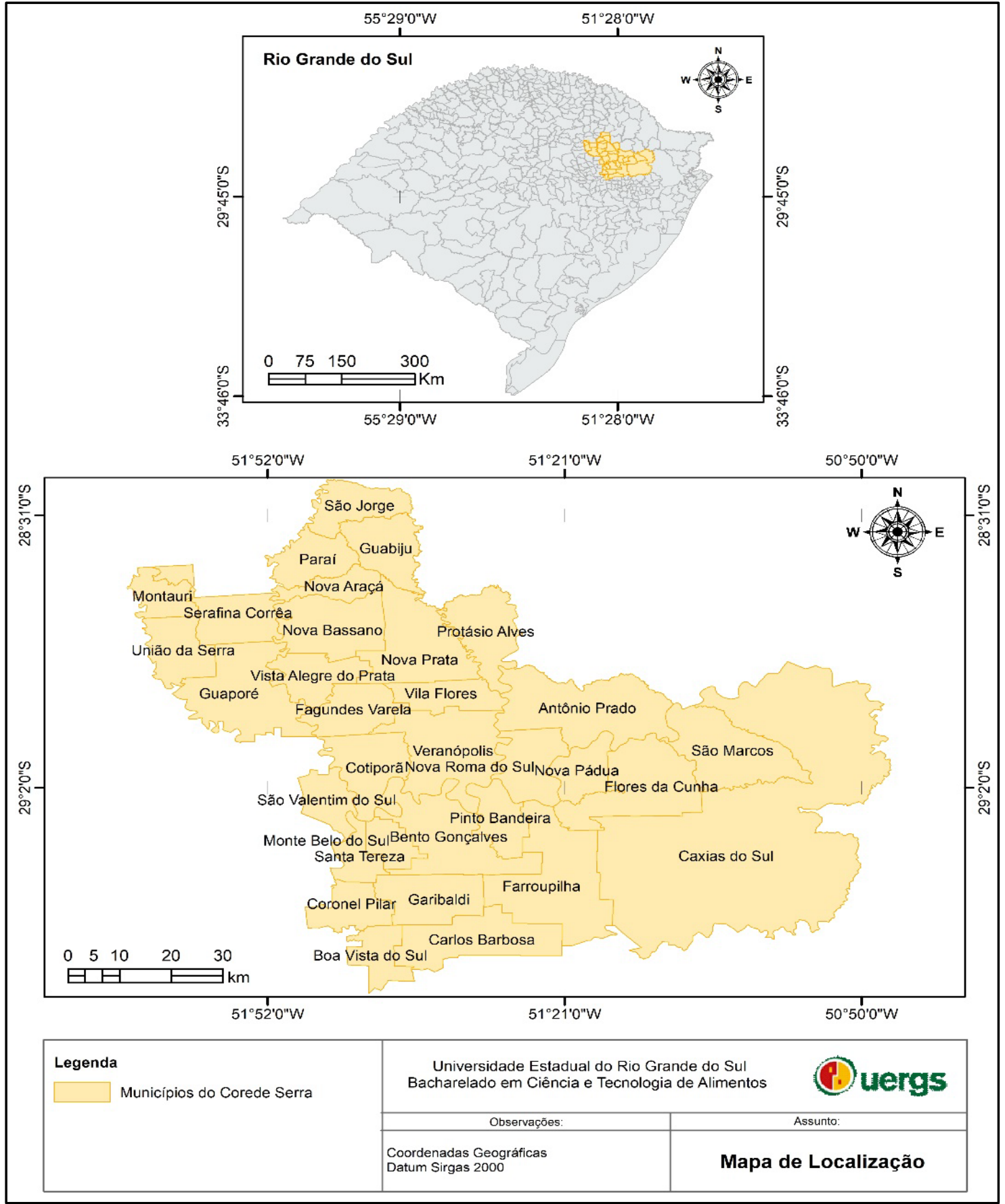

Figura 1. Mapa de localização do Corede Serra. 
O Corede é formado por um conjunto de instituições representativas da sociedade e têm por objetivo a promoção do desenvolvimento regional, harmônico e sustentável, através da integração dos recursos e das ações de governo na região, visando à melhoria da qualidade de vida da população, à distribuição equitativa da riqueza produzida, ao estímulo à permanência do homem em sua região e à preservação e recuperação do meio ambiente (Corede Serra, 2020).

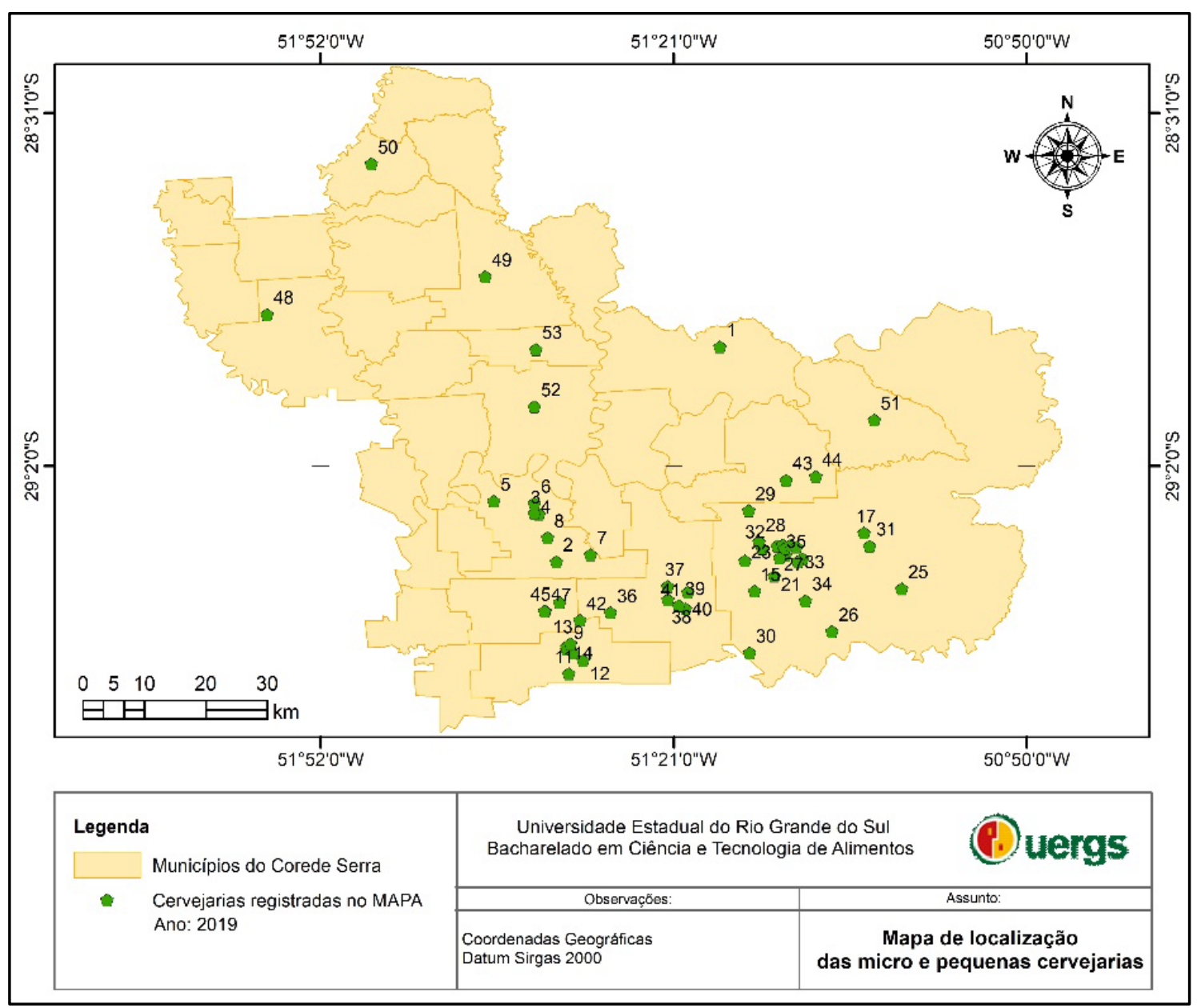

Figura 2. Mapa de localização das micro e pequenas cervejarias.

Aspecto como o da imigração, principalmente italiana, na região da Serra Gaúcha reitera a representatividade do empreendedorismo nesta região e justifica a preponderância da concentração de cervejarias no município de Caxias do Sul que remete à centralização comercial e à hierarquia econômica/industrial que está consolidada neste município perante os demais (Duarte et al., 2020). A Figura 3 mostra a quantidade de cervejarias artesanais por município no Corede Serra.

Destaca-se também para aspectos relacionados ao crescimento de startups e à implementação do e-commerce, objetivando a sobrevivência e a transformação da realidade do mercado, caracterizando assim as cervejarias artesanais como integrantes deste cenário inovador, favorecendo a aceitabilidade do mercado consumidor. 


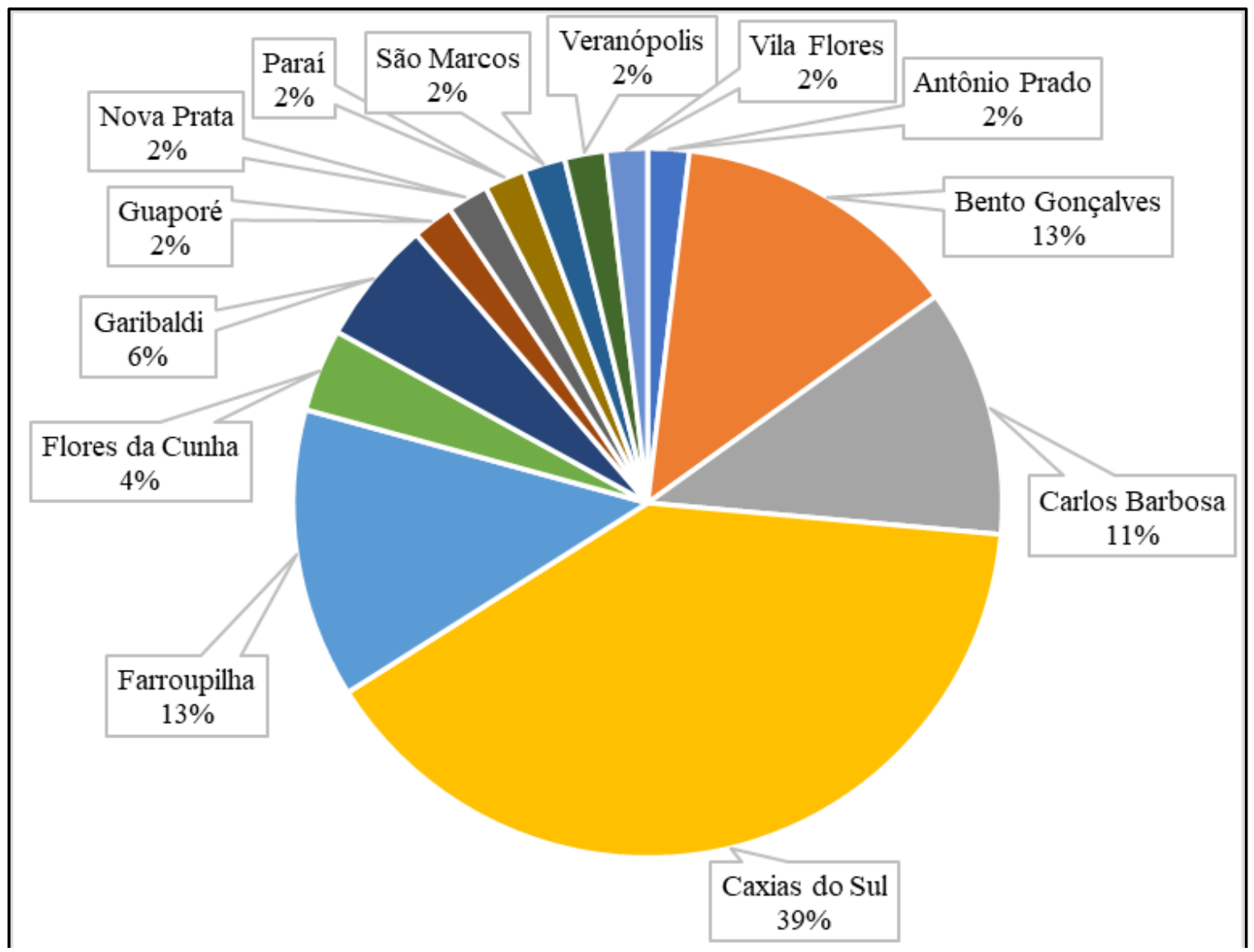

Figura 3. Cervejarias artesanais por município no Corede Serra.

Na região de estudo, foram listadas 53 cervejarias pelo mapa de localização pertencentes a esses municípios. A maioria delas foi criada no período entre 2014 e 2017. Dentre as cervejarias entrevistadas, a produção anual de cerveja varia entre 15.000 e 250.000 litros, com uma média de cerca de 20.000 litros mensais.

Outro ponto a ser destacado é quanto ao grau de impacto da sazonalidade na produção e venda das cervejas artesanais, aproximadamente $60 \%$ das vendas possuem alto grau de influência nas estações do ano. Os meses de maior produção são os períodos de altas temperaturas, entre novembro e fevereiro, principalmente dos estilos tipo Lager, Pilsen e Ipa. Também destacamos a produção dos tipos Ale, Weissbier e Pale Ale, com uma proporção intermediária na produção, e em menor número as cervejas Bock e Malzbier.

No inverno a pesquisa demonstra maior percentual de produção dos estilos Ipa, Pilsen, Bock, Ale, Weissbier, Pale Ale e Lager. Também há o acréscimo dos tipos Russian Imperial Stout, Irish Stout e Märzen e Stout citados por 5,9 \% dos entrevistados. Na Tabela1, apresenta-se a quantidade de vezes que os tipos de cervejas foram citados pelos entrevistados.

Quanto aos colaboradores presentes nas operações das cervejarias, a maior quantidade é de cinco pessoas, com um total de 51 colaboradores nas 17 cervejarias entrevistadas (média de três colaboradores por cervejaria). Dentre elas, 13 responderam que possuem proprietários, sócios ou membros da família como mão de obra ocupada no processo produtivo da cerveja, e a maioria deles possui formação específica para atuar no ramo, como mestres cervejeiros ou sommelier de cervejas. 
Tabela 1. Estilos produzidos conforme as estações verão e inverno.

\begin{tabular}{|l|c|c|}
\hline \multicolumn{1}{|c|}{ Estilos } & Verão & Inverno \\
\hline Lager & 13 & 4 \\
\hline Pilsen & 13 & 8 \\
\hline IPA & 11 & 6 \\
\hline ALE & 6 & 6 \\
\hline Weiss Bier & 6 & 5 \\
\hline Pale Ale & 5 & 7 \\
\hline Bock & 1 & 0 \\
\hline Malzbier & 1 & 1 \\
\hline Russian Imperial Stout & 0 & 1 \\
\hline Irish Stout e Märzen & 0 & 1 \\
\hline Stout & 0 & \\
\hline
\end{tabular}

O perfil do empresário responsável pelas cervejarias artesanais tem como base o princípio da autonomia, principalmente ao mudar de carreira e valorizar o trabalho por conta própria, da flexibilidade de horário, do controle do ritmo de trabalho, da inexistência de relações hierárquicas, dos rendimentos instáveis, da crença em uma relação virtuosa entre trabalho, mérito e salário e da responsabilização individual. A valorização do trabalho criativo, a educação para o empreendedorismo e o aperfeiçoamento tecnológico constituem a raiz para que novos processos de inserção profissional, pela via da inovação, sejam efetivados (Sgorla, 2016).

Para isso, ter uma formação universitária se torna imprescindível, assim o grau de formação da maioria dos proprietários são cursos de graduação (47\%), seguidos por cursos de mestrado, especialização, doutorado e ensino médio completos (Figura 4).

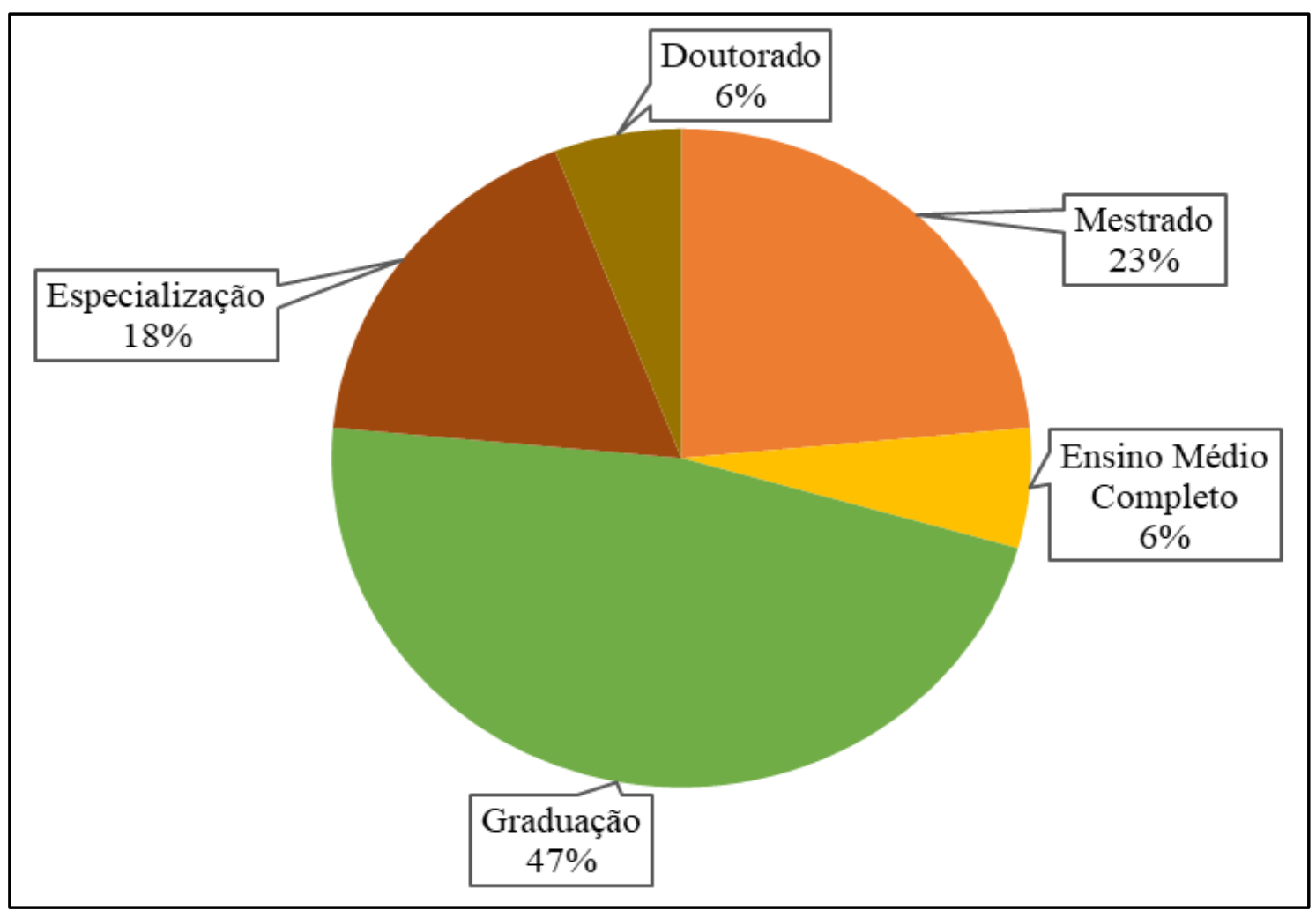

Figura 4. Grau de formação dos proprietários. 
Os dados, quanto ao grau de instrução dos colaboradores atuantes nas cervejarias estão descritos na Figura 5, com seu maior índice nos cursos de graduação $(41,2 \%)$, seguidos por ensino médio e fundamental completo, e com menor índice estão os profissionais com especialização e aqueles que não possuem colaboradores.

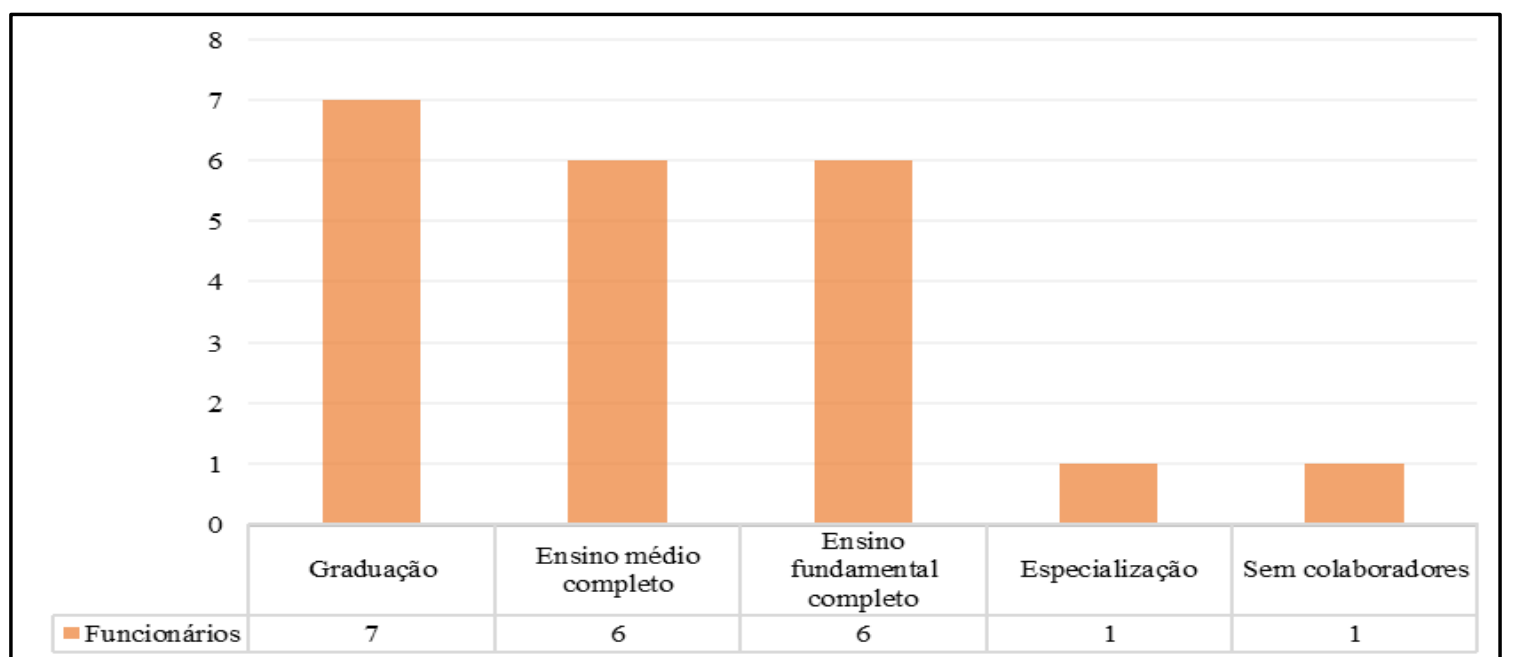

Figura 5. Grau de instrução dos colaboradores.

Com relação às vendas, os entrevistados apontam que elas são direcionadas prioritariamente para o comércio varejista, em um percentual de 82,4\%. Já com relação ao público consumidor foi feita a seguinte pergunta: "Caso direcione suas vendas para o varejo, qual é o perfil do seu consumidor?", trazendo as seguintes alternativas: homens em idade entre 18 e 30 anos, mulheres em idade entre 18 e 30 anos, homens com idade acima de 30 anos, mulheres com idade acima dos 30 anos. 0 maior percentual indicado são homens com idade acima de 30 anos $(78,6 \%)$.

Bares, restaurantes e lojas são os principais meios de escoamento, venda e divulgação dos produtos fabricados pelas micro e pequenas cervejarias ao apresentar a diversidade de possibilidades ao consumidor. Cerca de 53\% das cervejarias entrevistadas possuem pubs e lojas e a maioria deseja ampliar a empresa (cerca de 70,6\% delas), além disso, possuem como perspectiva de retorno do investimento aproximadamente doisanos após a criação do negócio.

Outro fator a ser considerado é em relação ao número efetivo de marcas de cerveja artesanal, o qual é expressivamente maior que o número de instalações industriais devido à existência de marcas "ciganas", que terceirizam a sua produção utilizando a capacidade de plantas já existentes (Krohn, 2018). A produção de cervejas por marcas ciganas é uma realidade da Serra Gaúcha, porém o MAPA ainda não contempla os dados referente à evolução do número de estabelecimentos no segmento artesanal, pois esta modalidade de cervejaria não é detentora de suas próprias estruturas produtivas (Nascimento, 2018).

0 mercado de cervejas artesanais é altamente competitivo devido à crescente quantidade de novos negócios nos últimos anos, com rótulos, sabores e estratégias diferenciadas. 0 setor se caracteriza por apresentar pouca diferença entre os preços praticados, marketing agressivo e muito valor agregado, por meio de produtos publicitários, como camisetas, canecas, copos e kits promocionais (Ramos e Pandolfi, 2019).

A fim de alcançar novos grupos de consumidores, mais estratificados, refinados ou segmentados, é necessário aplicar técnicas de inovação de marketing, e não de processos e 
produtos (Beni, 2017). Desta forma, foi importante o questionamento quanto à promoção dos produtos e marcas envolvidos com as cervejarias da Serra Gaúcha, onde 76,5\% dos entrevistados apostam na promoção dos produtos/marcas, caracterizando o tipo de marketing utilizado, dentre os seguintes: marketing digital, marketing de eventos, de relacionamento, marketing social, institucional, marketing de experiência e o tradicional.

Outro ponto importante para a venda do produto é o design das embalagens, citado por $100 \%$ das cervejarias entrevistadas. Levando em conta que a garrafa de cerveja é geralmente escura, âmbar, não permitindo a visualização do líquido, muitas vezes usa-se a cor do rótulo correspondente à cor da cerveja ou alguma característica ligada a sensorialidade. A construção do rótulo vai bem além de uma impressão colorida com dizeres e imagens, rotulagem é muito mais que apenas plotar em uma embalagem, é uma arte e veículo de comunicação com o consumidor, é falar sobre a beleza do processo de fabricação da cerveja e uma forma de enaltecer seus ingredientes (Serradourada, 2018).

0 rótulo sobre uma garrafa de cerveja artesanal apresenta, muitas vezes, uma grande quantidade de informações, incluindo o estilo (por exemplo, "American IPA"), amargor, intensidade da cor, nome da cerveja, graduação alcoólica, o nome da cervejaria e tipo de copo para beber a cerveja (como a "tulipa"). Uma cerveja artesanal também apresenta, em seu rótulo, selos, incluindo prêmios recebidos em concursos nacionais e internacionais que, muitas vezes, agregam valor ao preço da cerveja (Andrey, 2018).

Por gerar muitos resíduos da produção, a busca de soluções viáveis para eles é importante parte do processo, sendo que seu reaproveitamento pode trazer tanto benefícios ambientais como econômicos (Silva, 2020). Praticamente todos os entrevistados afirmaram que se preocupam com as questões ambientais e apontaram quais as práticas realizam na concepção da sustentabilidade que a indústria segue. As alternativas indicadas foram: gestão ambiental, produção sustentável, produção mais limpa $(P+L)$, ecoeficiência, avaliação do ciclo de vida, ecodesign, redução energética e logística reversa. A avaliação do ciclo de vida e o ecodesign não foram citados, e o maior percentual de práticas adotadas é a gestão ambiental (Figura 6).

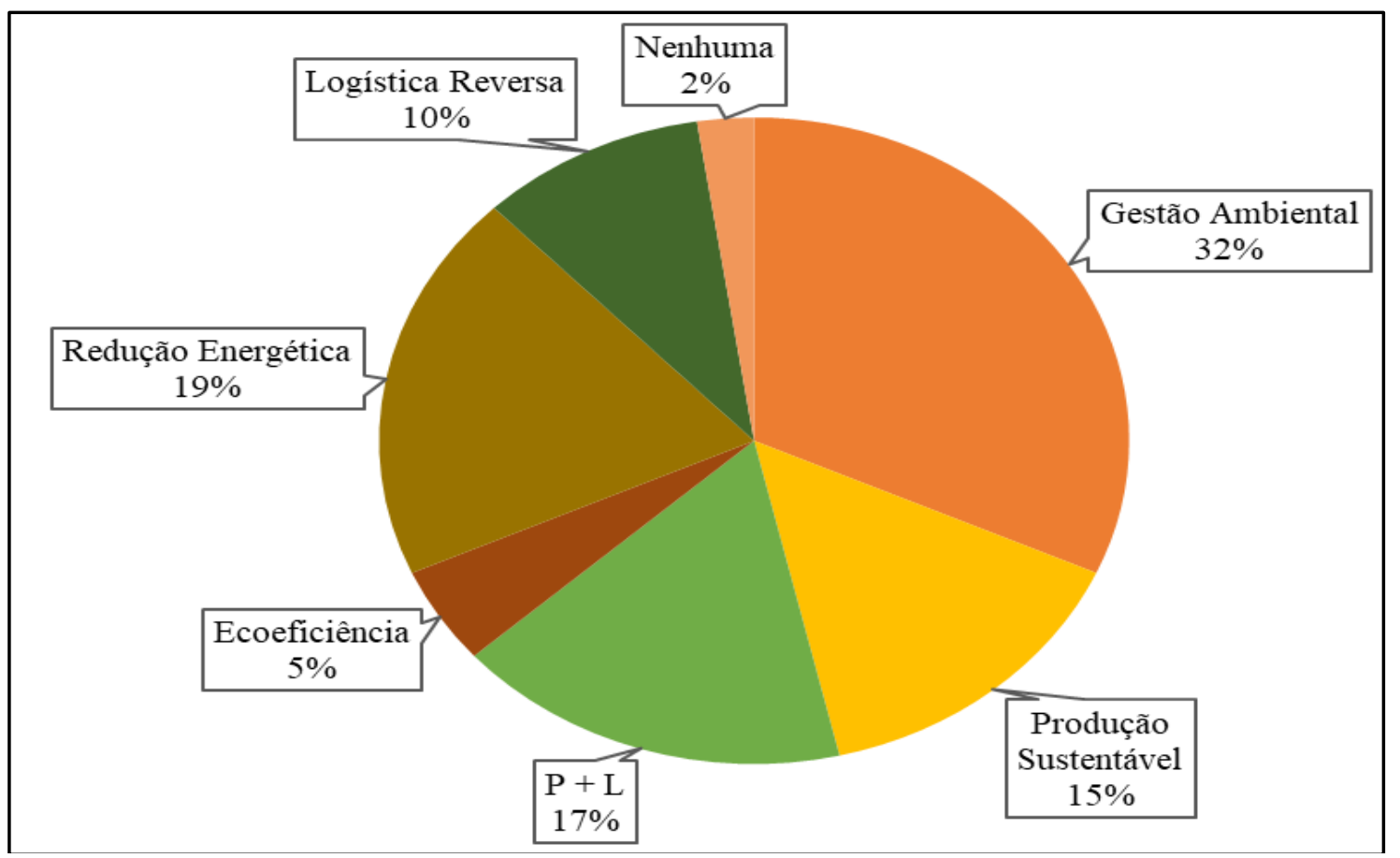

Figura 6. Práticas ambientais. 
0 processo de fermentação da cerveja consome muita energia e usa grandes volumes de água, especialmente no processo de mostura. A água é utilizada tanto para a produção da própria cerveja, quanto para limpeza e esterilização das várias unidades produtivas como as máquinas lavadoras de garrafas, gerando grandes volumes de efluentes residuais, sendo o recomendado para uma cervejaria eficiente o consumo de $4 \mathrm{a}$ 7 litros de água para produção de 1 litro de cerveja (Olajire, 2020).

A fim de quantificar os gastos mensais de água das cervejarias, foram sugeridas as seguintes faixas de valores, até $R \$ 1.000,00$, de $R \$ 1.001,00$ a $R \$ 2.000,00$, e acima de $\mathrm{R} \$ 2.001,00$. 0 resultado obtido traz os seguintes percentuais, $76,5 \%$ gastam até $\mathrm{R} \$ 1.000,00 ; 17,6 \%$ ficam na faixa entre $\mathrm{R} \$ 1.001,00$ a $\mathrm{R} \$ 2.000,00$ e $5,9 \%$ dos entrevistados apresentam gastos acima de $\mathrm{R} \$ 2.001,00$.

Algumas cervejarias da Serra Gaúcha possuem iniciativas para enfrentamento dos desafios ambientais, como a instalação de painéis para captação de energia solar, construção de cisternas para armazenamento da água da chuva, que é reutilizada na fabricação de rótulos das cervejas (Macedo, 2018), e criação de ovelhas para consumo do mosto produzido ao longo do processo cervejeiro, conforme visualizado em visita realizada na Cervejaria Leopoldina, localizada no município de Garibaldi-RS.

Nesse sentido, no que tange aos gastos mensais de energia elétrica, foram sugeridas as mesmas faixas de valores utilizadas na descrição dos gastos de água, obtendo os resultados da Figura 7.

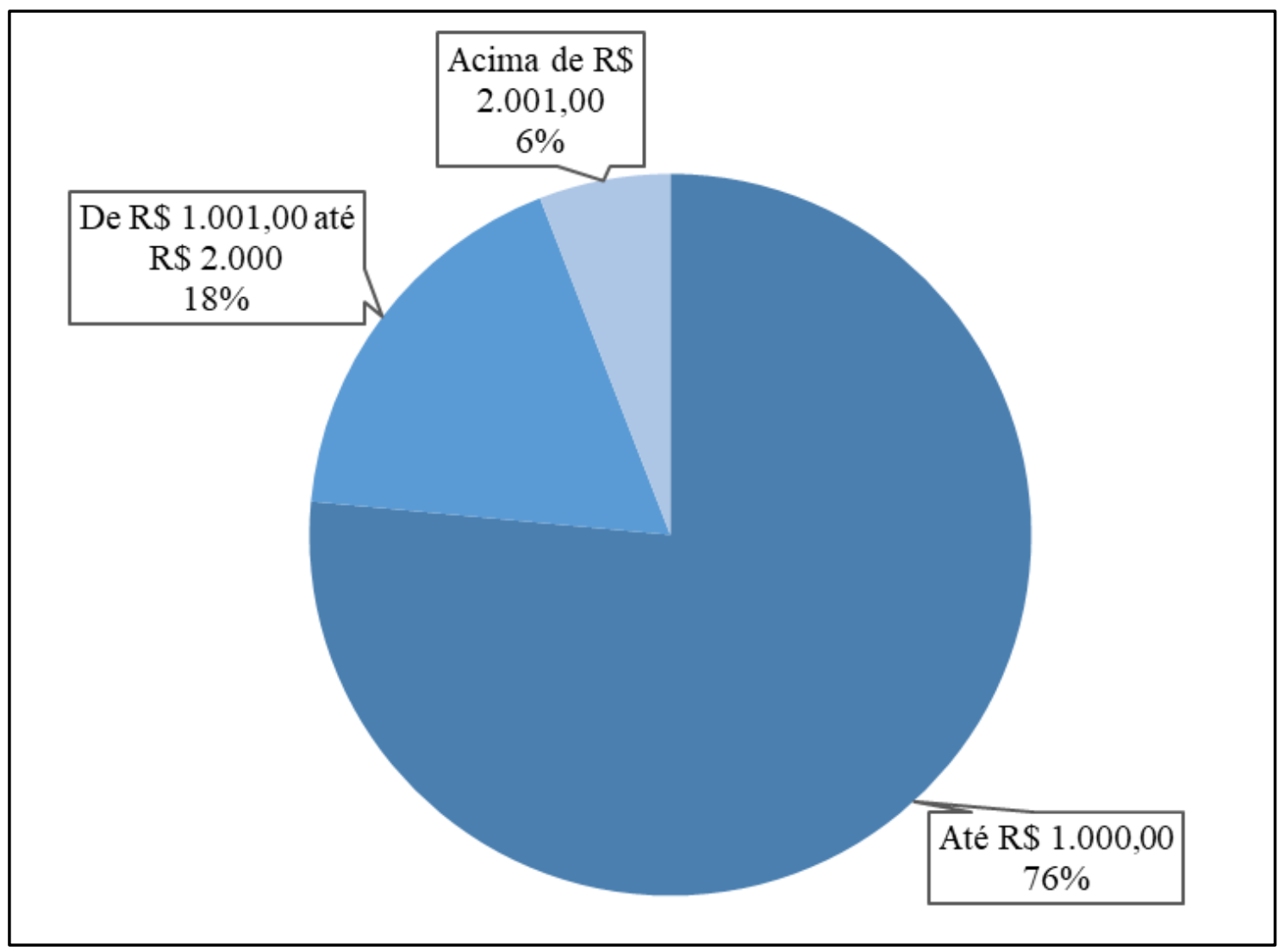

Figura 7. Gastos de água. 
Ao final do processo de fabricação da cerveja, há a geração de três resíduos principais: bagaço de malte, o trub (resíduo sólido decantado no fundo da panela de fervura) e a levedura residual (Ceccato, 2019). Sobre a destinação dos resíduos produzidos orgânicos, 52,9\% dos entrevistados têm como opção seu envio para algum serviço terceirizado efetuar o tratamento, $17,6 \%$ deles colocam todos juntos para o caminhão da prefeitura coletar e 11,8\% reutilizam na indústria. A figura 8 descreve todas as alternativas sugeridas aos entrevistados.

A partir da análise sobre a destinação dos resíduos orgânicos, podemos perceber que são necessárias ações no sentido de instruir os profissionais envolvidos com a produção cervejeira, para que haja um maior aproveitamento dos resíduos, especialmente aqueles que afirmam colocar tudo junto para o caminhão da prefeitura coletar. A diversidade de alternativas foi proposital para identificarmos com o máximo de veracidade o que ocorre no cotidiano das empresas, e termos um norteamento para auxiliar em um melhor aproveitamento dos resíduos. A entrega para algum terceiro mostra o quanto as empresas não possuem ciência ou não possuem condições estruturais para transformar os resíduos em algum subproduto e motivar alguma lucratividade, no que tange aos tratamentos e adoção de práticas ambientais já consolidadas no segmento.

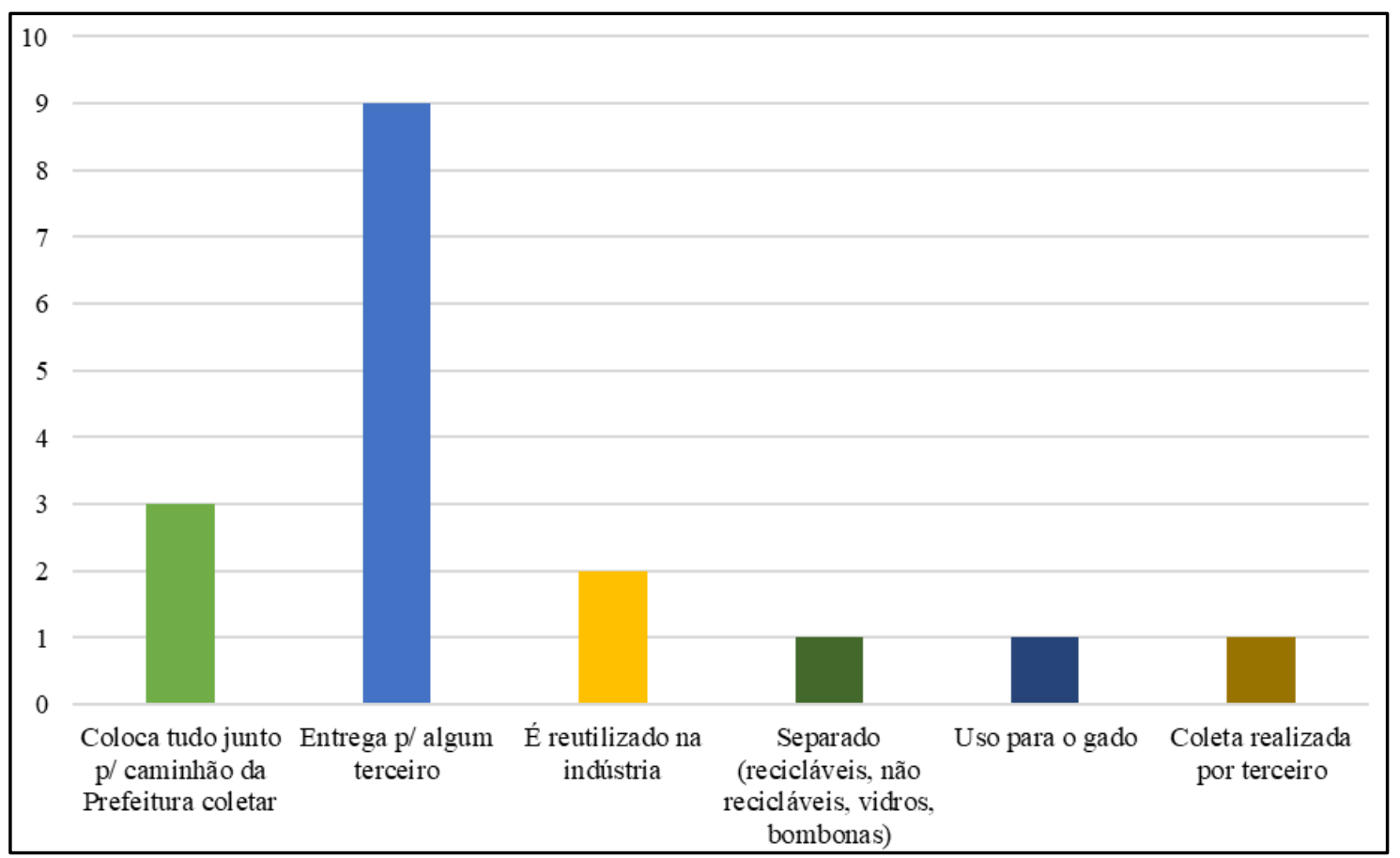

Figura 8. Destino dos resíduos orgânicos.

O bagaço é geralmente utilizado na alimentação animal de ruminantes e aves, e pesquisas abordam sua utilização também na alimentação humana, na forma de produtos de panificação (Saraiva et al.,2018). 0 bagaço de cevada também é chamado de bagaço de malte ou brewer's spent grain (BSG), polpa de cervejaria, borra de cervejaria e representa $85 \%$ do total de subprodutos gerados, sendo considerado o mais importante do processo de fabricação da cerveja, possuindo um elevado potencial de ser utilizado como ingrediente nas rações dos animais possuindo uma maior aceitação nas granjas de suínos que já fazem uso de alimentação líquida (Verde et al.,2019). 
Em relação ao lixo seletivo, $70,6 \%$ das cervejarias separam para coleta seletiva do município e $17,6 \%$ entregam para algum terceiro realizar o reaproveitamento ou descarte apropriado. Neste caso os principais tipos de resíduos gerados são vidros e alumínio provenientes da quebra de garrafas e amassamento de latas que ocorrem principalmente no processo de envase da cerveja (Delcor, 2019).

Dentre as facilidades para se estabelecer no negócio, são destacados os seguintes tópicos: paixão, processos produtivos, aquisição da matéria-prima, vontade de aprender e empreender, a qualidade do produto, pioneirismo no ramo e originalidade. Quanto às maiores dificuldades, são citadas: burocracia dos órgãos fiscalizadores, concorrência no mercado, questão financeira para atribuir maior investimento no negócio, alto custo dos equipamentos, sazonalidade de vendas e reconhecimento do mercado consumidor.

Para tentar driblar as dificuldades, a maioria das cervejarias efetua a distribuição do próprio produto e conforme descrito por Assoni (2018), aliar esforços financeiros e administrativos tem sido a saída para algumas cervejarias se manterem no mercado, apesar das dificuldades. Como o maior mercado das cervejas produzidas é a própria Serra Gaúcha, a logística própria torna-se eficiente. Para praticamente $100 \%$ dos entrevistados o mercado da Serra Gaúcha possui uma boa perspectiva de vendas.

Para maior entendimento dos tipos de cervejas que são feitas nas cervejas artesanais produzidas na Serra Gaúcha, foi feita uma visita técnica na Cervejaria Leopoldina, localizada no município de Garibaldi, RS. A Cervejaria Leopoldina, é uma marca de cervejas especiais do Grupo Famiglia Valduga, possui um amplo portfólio de cervejas com 13 receitas registradas no Ministério da Agricultura, Pecuária e Abastecimento, conforme informado pelo mestre cervejeiro.

São produzidas cinco variedades de Cervejas Especiais, armazenadas nas barricas de carvalho francês, Belgian Quadrupel, Old Strong Ale, Russian Imperial Stout, Belgian Tripel e Vitis Ale.

O caráter histórico da Serra Gaúcha é imperativo no que diz respeito à caracterização visual das cervejarias, desde a arquitetura rústica e afetiva presente nas fábricas, até a versatilidade de produtos feitos a partir das cervejas artesanais.

Os diferentes estilos existentes são inspirados na escola europeia e alemã cervejeira, mas a combinação de sabores cria uma identidade única, estreitando laços entre a comunidade e as indústrias cervejeiras, abrindo possibilidades de criação de novos estilos e sabores mais equilibrados, com maior apelo por parte do público consumidor.

A aposta no potencial turístico da Serra Gaúcha contribui significativamente para a abertura e progressão das cervejarias aqui situadas, que pretendem transformar a região em referência nacional e ponto de visitação obrigatório para os amantes de cerveja, com espaços interativos e cheios de histórias, mostrando que criar cervejas é uma atividade que envolve muito mais do que apenas conhecimento técnico. Os visitantes têm a oportunidade de circular por espaços temáticos, inserindo-se em uma jornada que passa pela magia alquimista da fábrica (Freitas, 2020).

Toda a valorização da produção cervejeira na Serra Gaúcha promove o crescimento dessa região e impulsiona a economia, trazendo mais empregos e desenvolvimento. É fundamental o incentivo do poder público para promover ainda mais o turismo, a redução da carga tributária e a potencialização das marcas, garantindo a abertura de novas cervejarias com layout diferenciado e a ampliação de técnicas inovadoras, que sirvam de diretrizes para novos empreendedores.

\section{Considerações finais}

O mercado cervejeiro da Serra Gaúcha está em franca expansão, contribuindo para o desenvolvimento da região e ao mesmo tempo fortalecendo a tradição de 
empreendedorismo e incorporando técnicas que aproximam o consumidor local de novas realidades, seja no sabor ou na arte da produção da cerveja artesanal.

Acredita-se que este trabalho possa contribuir de maneira eficaz com os diversos empreendedores cervejeiros, nos diversos municípios do nosso país, através do mapeamento das cervejarias e principalmente pelas diretrizes apresentadas para aprimoramento de técnicas que visem a preservação do meio ambiente, além de estratégias de marketing, da capacitação dos profissionais e ampliação das rotas cervejeiras que atraem turistas de vários lugares do Brasil e também do exterior, acarretando no desenvolvimento econômico e social de todos os envolvidos.

\section{Conflito de interesses}

Os autores declaram não haver conflito de interesses.

\section{Agradecimento}

Esse projeto contou com bolsa de Iniciação Científica da UERGS - Inicie/UERGS e bolsa de Iniciação Científica da Fundação de Amparo à Pesquisa do Estado do Rio Grande Do Sul - FAPERGS, entre 2020 e 2021.

\section{Referências}

Andrey, F. S. Cervejeiros artesanais: recursos, percursos e empresarialização de si. Revista de Ciências Sociais, n. 48, p. 21-37, 2018. https://doi.org/10.22478/ufpb.15175901.2018v1n48.37813

Assoni, R. L. F. A produção de cervejas especiais no Distrito Federal e seu potencial uso turístico. Brasília: Universidade de Brasília, 2018. (Trabalho de conclusão de curso).

Beni, P. F. Inovação e estratégia: um estudo no mercado de cervejas artesanais brasileiro. São Paulo: Universidade Presbiteriana Mackenzie, 2017. (Dissertação de mestrado).

Ceccato, B. T. Modelagem da cinética de secagem e caracterização físico-química do bagaço de malte da produção de cerveja artesanal. Curitiba: Universidade Tecnológica Federal do Paraná, 2019. (Trabalho de conclusão de curso).

Corede Serra. O Conselho Regional de Desenvolvimento Econômico e Social da Serra quem somos. Disponível em: <https://coredeserra.org.br/pagina/quem-somos>. Acesso em: 08 nov. 2020.

Delcor, A. L. A. Análise técnico-econômica de uma indústria cervejeira artesanal. Florianópolis: Universidade Federal de Santa Catarina, 2019.

Duarte, T. S.; Lourenço, W. M.; Fontana, G. Origem, ascensão e decadência das cervejarias no Estado do Rio Grande do Sul: um recorte espaço-temporal do Século XIX e XX. Caminhos de Geografia, v. 21, n. 73, p. 368-379, 2020.

Freitas, C. F. Edelbrau investe em complexo de turismo cervejeiro na Serra Gaúcha. 2020. Disponível em: <https://catalisi.com.br/edelbrau-investe-em-complexo-de-turismocervejeiro-na-serra-gaucha/>. Acesso em: 30 dez. 2020.

Krohn, L. V. H. Beber, fazer, vender: formação do mercado de cerveja "artesanal" no Brasil. São Paulo: Universidade de São Paulo, 2018. (Dissertação de mestrado). 
Luz, M. W. Um brinde a cerveja artesanal: A relação da cervejaria Stier Bier com o desenvolvimento socioeconômico de Igrejinha/RS. Taquara: Faculdades Integradas de Taquara, 2020. (Dissertação de mestrado).

Macedo, S. Copa do mundo da cerveja e brewpubs reforçam roteiro no Rio Grande do Sul. Folha de S. Paulo, 2018. Disponível em: <https://www1.folha.uol.com.br/turismo/ 2018/11/festival-e-bares-reforcam-cena-cervejeira-no-rio-grande-do-sul.shtml>. Acesso em: 27 fev. 2021.

MAPA - Ministério da Agricultura, Pecuária e Abastecimento. Anuário da Cerveja 2019. Brasília: MAPA, 2019. Disponível em: <http://www.agricultura.gov.br/assuntos/ inspecao/produtos-vegetal/pasta-publicacoes-DIPOV/anuario-da-cerveja-2019/view>.

Acesso em: 24 fev. 2021.

Marcusso, E. F. As microcervejarias no Brasil atual: sustentabilidade e territorialidade. Sorocaba: Universidade Federal de São Carlos, 2015. (Dissertação de mestrado).

Nascimento, R. J. M. Registro de marca produto: uma investigação sobre micro e pequenas cervejarias entre 2000-2017. Rio de Janeiro: Instituto Nacional de Propriedade Industrial, 2018.

Olajire, A. A. The brewing industry and the environmental challenges. Journal of Cleaner Production, v. 256, 102817, 2020. https://doi.org/10.1016/j.jclepro.2012.03.003

Ramos, G. C. B.; Pandolfi, M. A. C. A evolução do mercado de cervejas artesanais no Brasil. Revista Interface Tecnológica, v. 16, n. 1, p. 480-488, 2019.

Saraiva, B. R.; Vital, A. C. P.; Anjo, F. A.; Cesaro, E.; Matumoto-Pintro, P. T.Valorização de resíduos agroindustriais: fontes de nutrientes e compostos bioativos para a alimentação humana. Revista Pubsaúde, n. 1, a007, 2018. https://doi.org/10.31533/pubsaude1.a007

Serradourada, S. S. S. A rotulagem da cerveja artesanal e comum: uma análise dos elementos verbais e não verbais dos rótulos, do teor alcoólico e a visão do consumidor. Morrinhos: Instituto Federal Goiano, 2018. (Trabalho de conclusão de curso).

Sgorla, A. F. Lupulado e maltado: novas carreiras na construção social do mercado de cervejas artesanais. Anais do 40o Encontro Anual da ANPOCS, 2016. Disponível em: <http://www.anpocs.com/index.php/encontros/papers/40-encontro-anual-daanpocs/st-10/st31-3/10466-lupulado-e-maltado-novas-carreiras-na-construcao-socialdo-mercado-de-cervejas-artesanais>. Acesso em: 28 set. 2020.

Silva, N. S. R. Análise do reuso de leveduras no processo produtivo de cervejas artesanais. Tubarão: Universidade do Sul de Santa Catarina, 2020. (Trabalho de conclusão de curso).

Thurnell-Read, T. A thirst for the authentic: Craft drinks producers and the narration of authenticity. The British Journal of Sociology, v. 70, p.1448-1468, 2019. https://doi.org/10.1111/1468-4446.12634

Triola, M. F. Introdução à Estatística. 10. ed. Rio de Janeiro: LTC, 2011.

Verde, A. A.; Cucolo, M. C.; Oliveira, M. L. C.; Cavalieri, F. L. B.; Andreazzi, M. A.; Emanuelli, I. P. Destino sustentável de resíduos de cervejaria artesanal: um estudo de caso em uma granja de suínos. Revista Valore, v. 4, p. 84-93, 2019. 
Wallace, A. 'Brewing the truth': Craft beer, class and place in contemporary London. Sociology, v. 53, n. 5, p. 951-966, 2019. https://doi.org/10.1177/0038038519833913 seja devidamente citada. 